\title{
FINALE ALLEGRO, ACCELERANDO: REVISITANDO A ERRATA DE "A SAÍDA"
}

\author{
Flora Thomson-DeVeaux \\ Princeton University \\ Princeton (NJ), Estados Unidos
}

\begin{abstract}
Resumo: Uma reinterpretação de uma importante afirmação do narrador de Dom Casmurro: em vez de tomar o capítulo XCVII por seu valor de face, como uma errata, sugiro que, mais do que constituir uma ruptura, ele constitui uma manifestação de um fenômeno mais amplo na obra machadiana, em que o desfecho é convocado e apressado. Concordando com o tenor Marcolini que a vida é uma opera, chamaríamos esse fenômeno de "finale allegro".
\end{abstract}

Palavras-chave: errata; tempo; andamento; desfecho; literatura e música.

\section{Finale allegro, accelerando: revisiting the erratum of " $A$ saída"}

Abstract: A reinterpretation of a proclamation by the narrator of Dom Casmurro; instead of taking chapter XCVII at face value as an erratum, I suggest that, rather than constituting a rupture, it constitutes one manifestation of a larger phenomenon within Machado's works, ushering in and hastening the work's end. If we agree with the old tenor Marcolini that life is an opera, then, we might label this gesture a "finale allegro".

Keywords: erratum; time; pace; ending; literature and music.

Um ponto de ruptura, um lapso que revela motivos ocultos, a irrupção de uma crise: o capítulo XCVII de Dom Casmurro ("A saída"), dependendo de a quem se pergunte, poderia ser descrito de todas essas formas, ou talvez de nenhuma delas. Tratase de um momento em que o narrador corrige a si mesmo - procedimento que em si não tem nada de excepcional na trajetória do autor, mas que no entanto se tornou o centro das atenções de muitas das leituras do romance recentemente desenvolvidas e, em alguns casos, da obra de Machado como um todo. Para Silviano Santiago, ele exemplifica uma "retórica da verossimilhança" dentro da qual a imaginação e a

* Traduzido do inglês por Marcelo da Rocha Lima Diego e revisto pela autora. 
verossimilitude são sistematicamente privilegiadas, em detrimento da memória factual e da verdade, respectivamente. Já para Abel Barros Baptista, "A saída" contém a chave para a legibilidade do livro (e aqui eu peço perdão a Baptista por utilizar a palavra "livro" em sua acepção no senso comum, consagrada pelo uso, a bem da simplicidade) e lança luzes sobre a sistemática "ruína" da ficção machadiana. Sem entrar em um embate direto com nenhuma dessas interpretações, as quais ambas têm seus méritos, gostaria de propor uma mudança de perspectiva na análise desse capítulo, com menos foco na errata explícita, e mais naquilo que ela implica.

Após conseguir sair do seminário, o narrador (que será referido daqui em diante como Casmurro, mais uma vez a bem da simplicidade) subitamente declara:

[...] Aqui devia ser o meio do livro, mas a inexperiência fez-me ir atrás da pena, e chego quase ao fim do papel com o melhor da narração por dizer. Agora não há mais que levá-la a grandes pernadas, capítulo sobre capítulo, pouca emenda, pouca reflexão, tudo em resumo. Já esta página vale por meses, outras valerão por anos, e assim chegaremos ao fim. [... $]^{1}$

Conforme foi notado por Antonio Candido a propósito da querela entre os críticos a respeito da culpa ou inocência de Capitu, em qualquer um dos casos o resultado é o mesmo: seja ele um paranoico manipulador ou um virtuoso marido traído, o fato é que Casmurro destrói sua vida. ${ }^{2}$ De modo semelhante, espero evadir a questão da intenção específica do narrador ao fazer a sua errata e da necessidade de tal gesto. Se nesse momento há uma fratura no livro ou se a falta de papel não passa de uma desculpa vã, o resultado é o mesmo: o capítulo, em primeiro lugar, assinala um desfecho próximo, e, em segundo, se precipita na sua direção. Embora para Baptista o capítulo exemplifique a singularidade desse romance, a evocação engenhosa do fim da história (e do livro) é um recurso de modo algum limitado a Dom Casmurro. Na verdade, podemos entendê-la como um tema que aparece através de formas mais ou menos veladas em cada um dos trabalhos da chamada "segunda fase" de Machado: ela é como

\footnotetext{
${ }^{1}$ ASSIS, Machado de. Dom Casmurro. São Paulo: Ediouro, 2000. p. 207.

${ }^{2}$ CANDIDO, Antonio. Esquema de Machado de Assis. In: Duas Cidades, 1970. p. 25. Vários escritos. São Paulo: Livraria
} 
um gesto que o maestro faz com sua batuta, dando início ao que chamarei aqui de "finale allegro".

Comecemos expondo a análise que Abel Barros Baptista faz do romance, para que depois possamos melhor nos reposicionar em relação a ela. Baptista aborda Dom Casmurro, como um todo, através das lentes do pensamento de Derrida, enxergando no romance uma "vigilância da inscrição". ${ }^{3}$ Sendo a premissa do livro que ele é um livro em processo de ser escrito, o gesto dessa inscrição súbita implica a impossibilidade de tal supervisão. Baptista considera esse um movimento que coloca a natureza mesma do romance em jogo; a errata pode ser uma tentativa desesperada de colocar um trabalho digressivo novamente no rumo, ou uma correção que muda a natureza do trabalho no meio do caminho. O resultado é "a ficção do livro em que o livro é inviabilizado pela ficção", 4 em que uma fenda é aberta na obra, a revelar a impossibilidade da sua unidade. ${ }^{5}$ Embora Casmurro alegue que escreve para registrar suas lembranças da juventude, sem objetivo definido, o capítulo em questão traz uma nota nova e retumbante de urgência, questionando a noção mesma de "livro" e dando a ver o seu aspecto de construção precária, em que, uma vez derramada a argamassa, não se pode voltar atrás. A legibilidade de Dom Casmurro, argumenta Baptista, é decidida nesse ponto. ${ }^{6}$

Devido à consagração, em meio à crítica, de Casmurro, Aires e Brás como narradores autônomos, parece quase uma heresia levantar a cortina que recobre o verdadeiro mágico de Oz que é Joaquim Maria Machado de Assis. Mas se examinarmos os seus romances como "pessoas de uma só família, que a obrigação do pai fez sentar à mesma mesa" - conforme propôs Machado na introdução dos seus heterogêneos Papéis avulsos -, começaremos a suspeitar que, apesar da presença avassaladora do narrador no romance em pauta, o capítulo XCVII pode não ser um desvio da magnitude sugerida por Baptista. A convocação do fim e o aumento da velocidade, sejam por necessidade

3 BAPTISTA, Abel Barros. A reforma hermenêutica. In: Nenhum Brasil existe: pequena enciclopédia. Editado por João Cezar de Castro Rocha e Valdei Lopes de Araújo. Rio de Janeiro: UniverCidade, 2003. p. 548.

${ }^{4}$ BAPTISTA, Abel Barros. Autobibliografias: solicitação do livro na ficção de Machado de Assis. Campinas: Editora da Unicamp, 2003. p. 11.

${ }^{5}$ Idem, p. 82.

${ }^{6}$ BAPTISTA, Abel Barros. A reforma hermenêutica, cit., p. 549. 
ou por escolha, aparecem ao longo das obras da "segunda fase" machadiana, manifestando-se de diversas formas, mas sempre pairando no ar, conforme se vão ajustando aos diversos narradores e estilos dessa variada família - sintoma inevitável, talvez, do que Said chamou de "late style". ${ }^{7}$ Pegando emprestada a imagem do velho tenor Marcolini, de que a vida é uma ópera, percebemos que isto não se trata de uma mera questão de percepção do tempo narrado, mas também do andamento; ou seja, de uma mudança de ritmo que acontece não ao nível do tempo narrativo, mas do tempo controlado pelo narrador.

Alguns exemplos impactantes podem ser colhidos no cânone machadiano, a fim de ilustrar a proliferação desse gesto. Em "O alienista" - uma obra cujo narrador nos desafia de modo menos ostensivo do que Casmurro, e o faz basicamente nas margens do texto -, um momento similar a "A saída" ocorre apenas um capítulo antes do fim da obra; assim se conclui o capítulo 12:

O desfecho deste episódio da crônica itaguaiense é de tal ordem e tão inesperado, que merecia nada menos de dez capítulos de exposição; mas contento-me com um $[\ldots]^{8}$

O narrador de "O alienista" parece ser bastante seguro de si, e a passagem não se assemelha em nada a uma errata; mas as consequências serão as mesmas. Somos prevenidos de que o fim da narrativa está próximo e que daqui em diante haverá "pouca reflexão, tudo resumo". ${ }^{9}$ Há uma sensação de revisão e de retomada das rédeas; o que deveria ser dito em dez capítulos ou mais será em apenas um, tudo em função do propósito aparente de levar a história a cabo o mais rapidamente possível.

Nesse mesmo sentido, podemos olhar para o galhofeiro gesto constante ao fim de Esaú e Jacó, mais elaborado e desenvolvido em múltiplos capítulos. Deixando de lado as diferenças estruturais, ele é igualmente um vislumbre do fim. O antepenúltimo

\footnotetext{
${ }^{7}$ SAID, Edward. On late style: music and literature against the grain. New York: Pantheon Books, 2006. [Publicado no Brasil como: Estilo tardio. Tradução Samuel Titan Jr. São Paulo: Companhia das Letras, 2009.]

${ }^{8}$ ASSIS, Machado de. O alienista. New York: Luso-Brazilian Books, 2006. p. 44.

${ }^{9}$ ASSIS, Machado de. Dom Casmurro, cit., p. 207.
} 
capítulo beira uma alegre falta de sentido, anunciando a si mesmo e aos dois últimos capítulos já no título - "Que anuncia os seguintes":

Todas as histórias, se as cortam em fatias, acabam com um capítulo último e outro penúltimo, mas nenhum autor os confessa tais... Eu adopto o método oposto [...] indico o kilometro em que estamos da linha. ${ }^{10}$

Embora não haja nenhum erro da parte do narrador a ser reparado, nem uma tentativa de acelerar a narrativa, o efeito é notavelmente similar; onde outros narradores continuariam dando títulos normais, este argumenta que a honestidade é a melhor política e que vai dar nome aos bois, revelando que o fim está próximo. Ao intitular o penúltimo e o último capítulo precisamente como tais, ele apenas assume aquilo de que o leitor, sentindo o peso do livro e o virar das páginas, já se deu conta. O resultado é, novamente, uma precipitação rumo ao fim, evocado antes do tempo. (Levando este gesto às suas últimas consequências, alguém poderia imaginar um livro em que cada capítulo fosse intitulado - em numerais latinos tão impossíveis quanto exponenciais de acordo com sua distância em relação ao fim.)

Como última estação do nosso percurso pelo texto machadiano, no romance final do autor podemos encontrar uma pista para compreender o que foi primeiramente identificado em Dom Casmurro. No Memorial de Aires, um manuscrito-diário-livro em relação ao qual qualquer desfecho, do ponto de vista literário, seria inconcebível, devido à sua estrutura, podemos encontrar uma pista para entender o fenômeno do desfecho narrativo em Machado. A despeito do fim em aberto característico do Memorial, Aires é um narrador frequentemente pressionado pelo tempo. "Aqui referiu-me uma história que apenas levará meia dúzia de linhas", escreve em uma das primeiras entradas de seu diário, "e não é pouco para a tarde que vai baixando; digamo-la depressa". ${ }^{11}$ Tal como Casmurro fizera antes dele, este narrador vai ter de dar grandes saltos em sua história ("salto", aliás, é a palavra utilizada por Gilberto Pinheiro Passos para designar esse

\footnotetext{
${ }^{10}$ ASSIS, Machado de. Esaú e Jacob. Rio de Janeiro: W.M. Jackson, 1946. p. 420.

11 ASSIS, Machado de. Memorial de Ayres. Rio de Janeiro: W. M. Jackson, 1946. p. 39. (Entrada de 04.02.1888).
} 
gesto no Memorial) ${ }^{12}$ se quiser recuperar o ritmo da narração; e como Casmurro, que logo depois de anunciar que vai acelerar o ritmo da narração gasta ainda mais tempo com o seu eu de 17 anos, Aires claramente não consegue resumir em meia dúzia de linhas a história que ia contar. Essa entrada poderia facilmente servir como modelo para o conceito de finale allegro, não fosse uma frase ainda mais impressionante ao fim do livro, cunhada a partir de um provérbio francês: "[...] se os mortos vão depressa, os velhos ainda vão mais depressa que os mortos [...]". ${ }^{13}$ Gilberto Pinheiro Passos aponta para uma recorrência dessa frase ("les morts vont vite"), citação da balada Lénore, de Gottfried August Bürger, em vários momentos no romance; e ele nota que, apesar dessa afirmação, a narrativa do Conselheiro mostra que os mortos, de fato, "não se vão depressa", pois ancoram e marcam as vidas dos viúvos do elenco machadiano - não só não se vão, mas o fato de sua morte constitui uma espécie de fim palpável e presente. ${ }^{14}$ Com o tom desiludido, porém diplomático, que lhe é peculiar, Aires, contemplando o abandono do velho casal Aguiar, confirma que a velhice é ela mesma um finale allegro. Do mesmo modo, e nessa mesma entrada de seu diário, ele projeta essa mirada para as futuras gerações - "Viva a mocidade!". Não há nostalgia melancólica, nem tentativa de recuperar a juventude por meio da conquista de Fidélia; o seu tempo passou, e um velho ator deve saber abandonar os palcos no momento certo. Ao passo em que Pedro Meira Monteiro observa aí um rallentando e uma desaceleração gradual à medida que o futuro se torna definitivamente inviável, ${ }^{15}$ nós percebemos nessa distensão do ritmo uma antecipação, um travo prematuro do fim.

Considerando o aspecto profético do capítulo, então, começaremos a vislumbrar menos um Casmurro vacilante, de borracha em punho, riscando e redesenhando as linhas de seu texto - ele também vacilante -, e mais um Machado maestro. Onde Baptista identifica um capítulo em que um protagonista fragmentário

\footnotetext{
${ }^{12}$ PASSOS, Gilberto Pinheiro. As sugestões do Conselheiro: a França em Machado de Assis. São Paulo: Ática, 1996. p. 27.

${ }^{13}$ Idem, p. 284. (Entrada de 30.08.1889.)

${ }^{14}$ PASSOS, Gilberto Pinheiro. As sugestões do Conselheiro: a França em Machado de Assis. São Paulo: Ática, 1996. p. 39-42.

${ }^{15}$ MONTEIRO, Pedro Meira. O futuro abolido: anotações sobre o tempo no Memorial de Aires. Machado de Assis em linha n. 1, junho 2008. Rio de Janeiro; São Paulo: Fundação Casa de Rui Barbosa; Universidade de São Paulo, $2008 . \quad$ Acessível em: <http://machadodeassis.net/download/numero01/num01artigo05.pdf> Acesso em: 10.01.2012.
} 
denuncia a ruína do livro como um todo, onde "a falta de papel esconde e revela a impossível unidade do livro", ${ }^{16}$ daí talvez se possa extrair uma interpretação mais benevolente - ao entender momentos como esse não como gestos que tornam impossível a unidade do livro, mas sim como movimentos heterogêneos dentro de uma mesma sinfonia, dos quais o último marcará necessariamente o tempo mais vivo, se esforçando para chegar logo nos agradecimentos. Apesar das diferentes claves e das diferentes indicações de andamento, todas elas possuem algo em comum: uma antecipação do fim e uma aceleração da narração, em resposta. Faz sentido que isso se manifeste em Dom Casmurro na forma de uma rápida correção, uma vez que este é o modus operandi do narrador: conforme o próprio Baptista comenta, a tarefa mais difícil não é localizar todas as erratas do romance, mas sim fazer uma seleção moderada daquelas com as quais trabalhar. ${ }^{17}$

Lembremo-nos de que tal gesto é uma das artimanhas do prestidigitador "Machado maduro" e de que a "segunda fase" da obra de Machado tem início com as Memórias póstumas de Brás Cubas, um livro cuja dívida para com Laurence Sterne é declarada já no seu prefácio. De fato, se olharmos atentamente para Tristram Shandy, nos depararemos com uma passagem que revela certo grau de parentesco com o movimento retórico de "A saída", assim como com os outros allegrettos de Machado, não obstante as diferenças entre o escritor inglês e o brasileiro. Conforme prossegue em seu trabalho narrativo, Shandy revela-se um escritor tão inexperiente quanto Casmurro e que sofre da mesma tendência - talvez de modo ainda mais pronunciado - a sucumbir face à própria pena; e do mesmo modo que Casmurro gasta dois terços do livro narrando apenas sua adolescência, Shandy tece inúmeros capítulos a partir de um caso de poucos minutos e logo se vê enrolado no tecido de sua própria narrativa. "Is it not a shame to make two chapters of what passed in going down one pair of stairs?", lamenta no volume IV:

[...] for we are got no farther yet than to the first landing, and there are fifteen more steps down to the bottom; and for aught I know, as my father and my uncle Toby are in a talking humour, there may be as

\footnotetext{
${ }^{16}$ BAPTISTA, Abel Barros. Autobibliografias, cit., p. 122.

${ }^{17}$ Idem, p. 108.
} 
many chapters as steps:- - let that be as it will, Sir, I can no more help it than my destiny $[\ldots]^{18}$

O lamento em relação à passagem do tempo é o mesmo e se fará presente, de modo cada vez mais intenso, ao longo de todo o romance. A diferença fundamental é que enquanto Shandy se recusa a comprimir sua "Vida e opiniões" para recuperar tempo, Machado passa a marcha e acelera, antecipando e, em última instância, requisitando o fim. Para Casmurro não há a possibilidade de ter "as many chapters as steps": ele condensa certos eventos, passa batido por outros e até mesmo salta alguns, com o objetivo de chegar ao fim de modo elegantemente pontual. Mas por quê? "A causa secreta de um ato escapa muita vez a olhos agudos," lembra-nos Aires; ${ }^{19}$ mas podemos também aventar algumas outras possibilidades.

Uma hipótese é francamente niilista e ganha corpo sorrateiramente através da estrutura mesma do romance. Se olharmos para trás e prestarmos atenção em Brás Cubas, lembraremos o seu terrível delírio, a alucinação em que o universo se revela para ele em sua marcha do início dos tempos até o presente. O nascimento e a queda de civilizações, o amor, o ódio, palácios e melancolias, tudo em um ritmo vertiginoso e em constante aceleração. Já para o fim do episódio, "a rapidez da marcha era tal, que escapava a toda compreensão; ao pé dela o relâmpago seria um século". ${ }^{20}$ Podemos ler essa passagem junto com a urgência de Shandy, quando este se queixa de que "Time wastes too fast" ${ }^{\prime 2}$ enquanto ele escreve - e já então não há mais possibilidade de dar conta de nada, há simplesmente uma corrida desenfreada rumo ao esquecimento (o "estribeiro Oblivion"). Quando Brás desperta, a ventura humana dissolvera-se em névoa e, em seguida, ganhara a forma de um gato. "Nada há que esperar do porvir", comenta soturnamente Alfredo Bosi a propósito da cena; ${ }^{22}$ e, portanto - alguém poderia concluir -, não faz sentido ficar arrastando os acontecimentos desnecessariamente.

${ }^{18}$ STERNE, Laurence. Tristram Shandy: an authoritative text, the author on the novel, criticism. New York: Norton, 1980. p. 203.

${ }^{19}$ ASSIS, Machado de. Memorial de Aires, cit., p. 196.

${ }^{20}$ ASSIS, Machado de. Memórias póstumas de Brás Cubas. New York: Luso-Brazilian Books, 2004. p. 13.

${ }^{21}$ STERNE, Laurence. Tristram Shandy, cit., p. 430.

22 BOSI, Alfredo. Um nó ideológico. In: Ideologia e contraideologia: temas e variações. São Paulo: Companhia das Letras, 2010. p. 419. 
"Desnecessariamente", neste caso, seria o termo central do debate: não se trata de um lamento desesperado, do tipo que conclamaria todas as forças criativas restantes, mas sim uma estratégia narrativa desenganada e pragmática - talvez, nas palavras de José Paulo Paes, uma "lucidez algo doída". ${ }^{23}$ Notemos, de passagem, que fora o episódio do delírio, Memórias póstumas não possui outros momentos de exortação a um finale allegro, e isso por um motivo muito simples: a sinfonia de Brás não é ao vivo, e sim gravada, sendo tocado primeiro o seu fim, após o qual ela se torna mais ligeira e menos viva, ${ }^{24}$ na medida em que se encaminha para a conclusão.

Outra possibilidade de leitura retoma a experiência do livro em termos de um confronto com a mortalidade. Conforme vimos, em suas obras Machado se valeu desse allegretto não apenas no nível do tempo da narrativa, mas no do andamento do livro em si, como se o livro fosse uma criatura viva, caminhando a passos largos rumo à senilidade. Baptista mesmo reconhece que "A saída" é introduzida precisamente no momento de passagem da juventude para a idade madura, tendo a infância e a adolescência de Casmurro tomado a parte mais larga do livro; o meio do livro corresponderia ao meio da narrativa, que equivaleria à metade de sua experiência de vida, mas a idade trota ainda mais ligeira quando a morte não se trata mais de uma questão filosófica, mas sim de uma realidade física bastante concreta. Assim como Marcolini a vida era uma grande ópera, podemos imaginar esse recorrente finale allegro como um modo de Machado dar vida (e morte, posto que ela faz parte da vida) aos seus livros. Passado o ponto de viragem da ação, o fim começa a se insinuar, indo além da sua condição de simples conclusão e passando a contaminar o título de capítulos e até a numeração deles. Não há que se esperar mais nada: tal como Aires, o livro reconhece que já não é "deste mundo", ${ }^{25}$ porém em vez de voltar os olhos para trás, ele se precipita atabalhoadamente na direção oposta: os últimos capítulos não se sustentam por si só, eles precisam anunciar a sua condição de derradeiros; Aires percebe o seu envelhecimento não como mais uma fase da vida, mas como uma preparação para a

23 PAES, José Paulo. Um aprendiz de morto. In: Gregos \& baianos: ensaios. São Paulo: Brasiliense, 1985. p. 32.

${ }^{24}$ ASSIS, Machado de. Memórias póstumas de Brás Cubas, cit., p. 145.

${ }^{25}$ ASSIS, Machado de. Memorial de Aires, cit., p. 268. 
morte. ${ }^{26}$ A aceleração estrutural transforma a experiência do livro em um espelho da experiência da vida mesma, conferindo à obra um sentimento de finitude desprovido de nostalgia - felizmente, pois Aires detestaria um desfecho sentimental.

Vista deste ângulo, a errata de Dom Casmurro trata não mais da questão de como o livro se desenvolve no presente como uma estrutura fragmentária e mutável, e sim consiste em um modo de relacionar a narrativa à materialidade do livro: mais do que transcender sua condição material, essa narrativa de maturidade reconhece sorrateiramente que, em determinado momento, apesar de sua abundância, o papel vai acabar. No início de Autobibliografias, Baptista repudia a ideia de "enredo", ou até mesmo de "romance", sendo este definido por "um princípio e um fim claramente delimitados e a exigência de uma linha reta que os una, sem desvios nem rupturas"; ${ }^{27}$ é claro que os romances da segunda fase de Machado estão mais próximos dos rabiscos erráticos de Tristram Shandy do que de qualquer coisa que se assemelhe a uma narrativa linear, porém o fim, conforme observamos, desempenha um papel importante nessas obras tardias. Os momentos que assinalamos são aqueles em que o fim é marotamente antecipado, de modo a acelerar o andamento e preparar a orquestra para a nota final; não se trata de um gesto radicalmente a contrapelo do livro, que revele o seu processo constitutivo, mas sim de um movimento que endossa a estrutura do livro e a inevitabilidade do seu fim - e que, deste modo, menos enfraquece do que fortalece o livro, material e metaforicamente. Afinal de contas, como o próprio Baptista reconhece, é na existência de um fim que se radica a possibilidade mesma do romance. ${ }^{28}$

Assim, a evocação do fim em Machado parece se fazer mais no plano conceitual do que no estilístico, pois sua natureza é proteica, buscando modos de se manifestar em romances diversos, com estruturas e narradores inteiramente distintos. Enquanto Casmurro gagueja e se corrige, o suposto Aires-narrador de Esaú e Jacó e o leitor anônimo das crônicas de Itaguaí de "O alienista" optam por títulos concisos e honestos, e o Aires-memorialista se entrega vagarosamente às próprias sombras; contudo o gesto fundamental permanece inalterado. E o que poderia parecer uma falta

\footnotetext{
${ }^{26}$ PAES, José Paulo. Um aprendiz de morto, cit., 34.

${ }^{27}$ BAPTISTA, Abel Barros. Autobibliografias, cit., p. 53.

${ }^{28}$ Idem, p. 115.
} 
de horizonte, um "futuro abolido", é na verdade a afirmação de um horizonte qualitativamente distinto, aquele do livro como uma estrutura inevitavelmente finita. $\mathrm{O}$ fim como uma constatação filosófica (a revelar um narrador niilista) e material (a revelar um autor galhofeiro) acaba por dar forma e sentido com precisão à narrativa, impondo uma espécie de unidade aos fragmentos variados e digressivos do conjunto. Isso para não mencionar, é claro, a atmosfera carregada que o finale allegro estende sobre esse elenco de narradores machadianos, a um só tempo amedrontadora e sedutora: de Casmurro a Aires, todos eles estão cientes de que a última página está próxima e apressam suas penas em resposta, não sem certo prazer.

Referências:

ASSIS, Machado de. O alienista. New York: Luso-Brazilian Books, 2006. . Dom Casmurro. São Paulo: Ediouro, 2000. . Esaú e Jacob. Rio de Janeiro: W.M. Jackson, 1946. . Memorial de Ayres. Rio de Janeiro: W. M. Jackson, 1946. . Memórias póstumas de Brás Cubas. New York: Luso-Brazilian Books, 2004.

BAPTISTA, Abel Barros. Autobibliografias: solicitação do livro na ficção de Machado de Assis. Campinas: Editora da Unicamp, 2003.

- A reforma hermenêutica. In: . Nenhum Brasil existe: pequena enciclopédia. Editado por João Cezar de Castro Rocha e Valdei Lopes de Araújo. Rio de Janeiro: UniverCidade, 2003.

BOSI, Alfredo. Um nó ideológico. In: variações. São Paulo: Companhia das Letras, 2010. Ideologia e contraideologia: temas e

CANDIDO, Antonio. Esquema de Machado de Assis. In: . Vários escritos. São Paulo: Livraria Duas Cidades, 1970.

MONTEIRO, Pedro Meira. O futuro abolido: anotações sobre o tempo no Memorial de Aires. Machado de Assis em linha n. 1, junho 2008. Rio de Janeiro; São Paulo: Fundação Casa de Rui Barbosa; Universidade de São Paulo, 2008. Acessível em: $<$ http://machadodeassis.net/download/numero01/num01artigo05.pdf $>$ Acesso em: 10.01.2012.

PAES, José Paulo. Um aprendiz de morto. In: Gregos \& baianos: ensaios. São Paulo: Brasiliense, 1985. 
PASSOS, Gilberto Pinheiro. As sugestões do Conselheiro: a França em Machado de Assis. São Paulo: Ática, 1996.

SAID, Edward. On late style: music and literature against the grain. New York: Pantheon Books, 2006.

SANTIAGO, Silviano. Retórica da verossimilhança. In: . Uma literatura nos trópicos: ensaios sobre dependência cultural. São Paulo: Perspectiva, 1978.

STERNE, Laurence. Tristram Shandy: an authoritative text, the author on the novel, criticism. New York: Norton, 1980.

Flora Thomson-DeVeaux é formada em Spanish and Portuguese Languages and Cultures pela Universidade de Princeton, além de tradutora e blogueira. Atualmente escreve um livro sobre a vida e a obra de Santiago Badariotti Merlo, mordomo da família Moreira Salles. E-mail: fthomson@princeton.edu

Recebido: 15.03.2013

Aprovado:17.06.2013 